\title{
An Extraordinary Obituary for an Extraordinary Man: Attila Naszlady
}

On $20^{\text {th }}$ January 2015, Attila Naszlady, passed away at the age of 84 . The fact that Attila died while playing tennis clearly shows that he was not an ordinary man. His extraordinary character is the reason why I take the liberty to write this obituary in a somewhat unusual way.

I kindly ask the reader to forgive me for not listing all his titles, prizes, awards, scientific and social positions, and memberships. For those, who did not have the opportunity to know him in person, he was born in Budapest, studied medicine and specialized in cardiology. He was the founding member, and later the president of the Medico-Biological Section of the John von Neumann Computer Society (Budapest, Hungary). He has been representing Hungary both in IMIA and EFMI for many years, and became president of EFMI (1998-2002, the first president from a former socialist country. Beyond his activity both in cardiology and medical informatics, he acted as chief director in different hospitals, was active in many social affairs, and gained a high reputation in every field. And - of course - he was an excellent tennis player.

I would like to share with the readers some of the many stories I have in my memory about him that characterize his extraordinary personality.

In the early 90 s, when I was a quite young physician, I applied for a grant to support work on the Hungarian adaptation of SNOMED II that was very different from what SNOMED CT is today. My application did not fare well in the peer review. Since some of the referees pointed to Attila's former work, I decided to visit him at the John von Neumann Computer Society, and discuss the matter. It was my first face-toface meeting with him. At first, he was critical about my plans, but as the discussion went on, we delved deeper into the

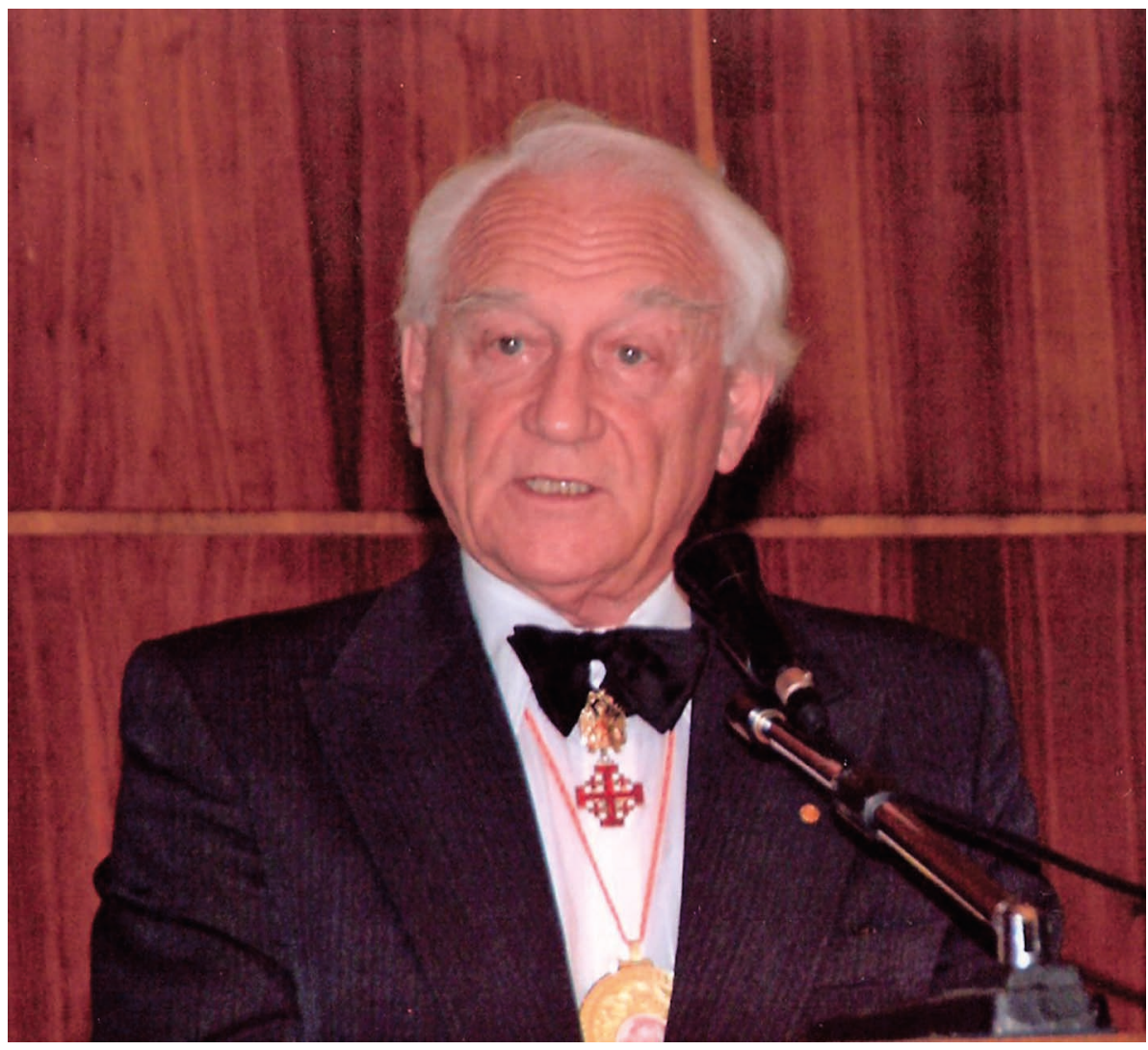

Fig. 1 Prof. Dr. med. Attila Naszlady during a lecture wearing the cross of the Equestrian Order of the Holy Sepulchre of Jerusalem. Source of photo: http://naszlady.synthasite.com/

problem of medical concept representation. At the end, he was still not supporting my plans but he invited me to act as the secretary of the Medico-Biological Section he was chairing at that time. He was strong in his decisions but open-minded at the same time. Later on, I succeeded to receive a grant for SNOMED adaptation, and despite the fact that the result of the project was satisfactory, we had to realize that neither SNOMED II nor SNOMED III could fulfill our expectations - however, the reasons were quite different from Attila's arguments. Wise men sometimes see in a prob- lem more than they can express - and Attila obviously was a wise man. Beyond being wise, Attila was inventive. For instance, he taught me how to prepare fried eggs with an electronic iron - in case of necessity.

To find your ways in unexpected situations is an obvious merit of a researcher. But in the case of Attila, it never meant to find immoral trade-offs. His common sense and scientific invention skills were based on a strong integrative view of the reality. In this view, medical informatics was an activity that should be practiced at three levels that I will try to interpret using my own words. 
On the basic level, there is the representation. We collect data about patients. This can be done in a practical but rather administrative way that is not very interesting from the scientific point of view, but this is the basis, the foundation of any further activities.

The second level is the analysis. Once the data is stored in computers, we have the opportunity to analyze it very efficiently, in large amounts and at high speed. "Amount" and "speed" are notions that people are fond of in our modern life. But such notions never satisfied Attila. As a wise man, he saw very clearly that collecting a huge amount of data is a poor way to understand things. There are two problems when having too much data. The first is noise, and the second concerns validity. Noise is not something that wise men like. I will come back to the problem of validity since this was a point that was very deterministic in Attila's intellectual habits.

The third level is modeling. In Attila's view the human body - as any other system - is a structure that functions according to certain laws. The 'art of medicine' is noth- ing but carrying out actions on the human organism, based on our knowledge about the laws of this system with the intent to evoke a desired response. These four things: the action, the system, the laws, and the response form the model, and that's why modeling is the highest level of our discipline.

It is very clear that having a good model is much more advantageous than just having an analytic view on our data. On the other hand, having a false model can be a much more serious problem than having nothing. And this is why Attila was very sensitive to the validity. Many times, he made serious warnings about - as he called - disinformation - be it either intentional or just a result of ignorance. In his mind, truth had some divine or sacral nature and he was a strong believer. As a logical consequence, disinformation would have an evil nature.

I cite here a sentence he presented many times in his various lectures: "Disinformation is more dangerous than the atomic bomb, because it can completely destroy not only our lives and material goods but our spiritual world too."
This statement is very characteristic of his personality and believes, and very close to one of the thoughts of a famous Hungarian writer Frigyes Karinthy. Karinthy argued that if human life was eternal by nature, than life would be the greatest of all goods, and killing would be the most serious sin. However, since eventually all of us would die, someone who deprives us from the sense of our life commits a more serious sin than someone who takes our lives.

I do not know if Attila ever read this argument by Karinthy, but undoubtedly, he would agree. And there was no force in the world, including the dark age of socialism in Hungary that could deprive Attila from the sense of his life. The heritage of his life is now in our hands, and all the medical informatics community has the responsibility to take his above cited warning seriously.

By György Surján MD PhD

National Healthcare Service Center

Budapest, Hungary

surjan.gyorgy@aeek.hu 